\title{
Thalamic Mechanisms in Language and Rhythm (Temporal Perception and Expression) - Comparison of Cortical and Thalamic Damaged Patients from the Neurobehavioral Aspect
}

\author{
Hiroko Nakamura \\ Department of Neurology, Institute of Brain Diseases, \\ Tohoku University School of Medicine, Sendai 980
}

\begin{abstract}
Nakamura, H. Thalamic Mechanisms in Language and Rhythm (Temporal Perception and Expression) - Comparison of Cortical and Thalamic Damaged Patients from the Neurobehavioral Aspect. Tohoku J. Exp. Med., 1990, 161, Suppl., 183-202 — We investigated the relationship between language disturbances and the impairment of rhythmic capabilities (temporal perception \& expression) in the patients with thalamic hemorrhage and compared them to patients with cortical lesions to probe the relationship of the thalamus to the mechanism of aphasic symptoms. 101 right-handed individuals, including 12 with thalamic hemorrhage, were studied to analyze language (verbal) and rhythmic (non-verbal) functions. Comparison of left- and right-hemisphere damaged patients revealed significant hypofunction of language and rhythmic capabilities in the group with lesions of left hemisphere. Some correlation could be seen between the rhythm disturbance and the language impairments in terms of severity and types. In contrast, the patients with thalamic hemorrhage showed a dissociation between the severely abnormal rhythm (non-verbal) and milder language (verbal) impairments. The language function values were constantly higher in the cases with thalamic hemorrhage than with cortical damages, while rhythmic capabilities were reduced, a tendency unlike that of the group with cortical damages. These findings suggest that language is primarily a function of the cerebral cortex of the dominant hemisphere, and that the thalamic area, necessary for the timing mechanism (rhythmic function), plays a part in the overall mechanism of aphasic symtomatology. - thalamic hemorrhage; thalamic aphasia; rhythmic capability; cortical function; thalamic function
\end{abstract}

In general, linguistic competence and speech faculties are subserved by Wernicke's and Broca's zones of the dominant hemisphere (Penfield and Roberts 1959), and aphasic syndromes are generally associated with cortical lesions involving these areas (Luria 1977).

Recent observation from clinico-pathologic studies, stereotaxic surgery, and electrical stimulation via depth electrodes, however, have prompted interest in the

This paper is part of my doctoral dissertation submitted to the Tohoku University School of Medicine. 
hypothesis that cortico-thalamic systems co-sponsor intellectual activity in man. Penfield and Roberts (1959), based on the data of their electrical stimulation studies, suggested that subcortical structures, particularly the thalamus, subserved speech functions comparable to those of the cortical speech area. The Penfield hypothesis was supported by a number of investigators (Osgood and Miron 1963 ; Schuell et al. 1964 ; Lenneberg 1967 ; Ojemann et al. 1968; Ojemann and Ward 1971).

Other investigators, however, have noted problems with this hypothesis. Alexander and Loverme (1980), Naeser et al. (1982), Damasio et al. (1982), Benson (1979) and others have pointed out that the aphasic syndromes following damage to the thalamus and nearly subcortical structures differ from those caused by damage to cortical language areas. These studies have shown that although aphasia does not inevitably follow left-sided thalamic ablations or stimulations, it does occur often.

Our previous reports (Nakamura 1980 ; Nakamura et al. 1981a, b) suggested that brain damaged patients, including those with thalamic lesions, had remarkable impairments of rhythmic capabilities (temporal perception and expression). More specifically, patients with thalamic lesions showed a marked rhythm disturbance despite relatively mild aphasic symptoms. This finding was quite different from those in cortically damaged patients.

In the present study, we investigate the relationship between language (verbal) disturbances and the impairment of rhythmic (non-verbal) capabilities in patients with thalamic area hemorrhage and compare them to patients with cortical lesions. Based on these observations, the relationship of the thalamus to the mechanism of aphasic symptoms is discussed.

\section{Clinical Materials and Methods}

Clinical materials. One hundred one right-handed individuals (Table 1), including 12 patients with thalamic hemorrhage were studied : 48 patients with cortical lesions of left hemisphere were aphasics (Table 2). 20 patients with cortical lesions of right hemisphere were non-aphasic (Table 3 ), and 14 of these 20 cases showed some neuropsychological deficits without dementia. Their mental status were evaluated based on the neurobehavioral evaluation procedures (Cummings and Benson 1983). Our twelve thalamic patients (Table 4) has CT evidence of primary thalamic hemorrhage (Fig. 1). Their neurological findings were based on the examination on admission. Prognosis was evaluated according to the ability to perform activities of daily living (ADL) 2 months after onset (Table 4). All of these 81 patients who had cerebrovascular diseases and 20 normal controls were examined to analyze their language and rhythmic functions.

Methods. The Standard Language Test for Aphasia (SLTA), a validated Japanese aphasia evaluation plus some tasks demanding short composition were administered to evaluate language function. 18 items (Table 5) were checked. While, the Asian Rhythm Test Battery and the Electro-Tapping Graph what is called "Tapping-Measure" were devised and employed to analyze and to evaluate rhythmic capabilities in the process of audio-motor coordination. This Asian Rhythm Test Battery was based on our neuropsychological model (Nakamura et al. 1981a) which was proposed for the relationship between 
TABLE 1. Materials

\begin{tabular}{clc}
\hline \multicolumn{1}{c}{ Group } & \multicolumn{1}{c}{ Subjects } & Cases \\
\hline Cortical damaged & & \\
Disturbance of left hemisphere & Non-fluent aphasics & 23 \\
& Fluent aphasics & 25 \\
Disturbance of right hemisphere & Non-aphasics & 20 \\
Thalamic hemorrhaged & & \\
Left thalamic lesion & Quasi-aphasics & 7 \\
Right thalamic lesion & Non-aphasics & 6 \\
Normal control & Healthy & 20 \\
& & 101 \\
\hline
\end{tabular}

TABLE 2. Aphasic cases with the cortical lesions of left hemisphere

\begin{tabular}{ccc}
\hline \multicolumn{1}{c}{ Group } & $\begin{array}{c}\text { Age } \\
\text { (years) }\end{array}$ & Cases \\
\hline $\begin{array}{c}\text { Non-fluent aphasics } \\
\text { Broca's aphasia } \\
\text { Transcortical motor aphasia }\end{array}$ & $26-71$ (mean 41.3) & 15 \\
Fluent aphasics & $38-79$ (mean 54.5) & 8 \\
Wernicke's aphasia & & 16 \\
Conduction aphasia & $33-68$ (mean 46.1) & 9 \\
Total & $41-63$ (mean 53.3) & 48 \\
\hline
\end{tabular}

TABLE 3. Non-aphasic cases with the cortical lesions of right hemisphere

\begin{tabular}{llcc}
\hline \multicolumn{1}{c}{ Group } & Lesion's location & $\begin{array}{c}\text { Age } \\
\text { (years) }\end{array}$ & Cases \\
\hline $\begin{array}{c}\text { Expressional impairments } \\
\text { Pereceptual impairments }\end{array}$ & Frontal/parietal lobe & $18-69$ (mean 42.5) & 8 \\
Temporal/parietal lobe & $32-71$ (mean 48.5) & 6 \\
occipital lobe & & 6 \\
Total & Frontal/parietal lobe & $31-58$ (mean 43.0) & 6 \\
occipital lobe & & 20 \\
\hline
\end{tabular}


TABLE 4. Clinical backgrounds of 12 cases of thalamic hemorrhage

\begin{tabular}{|c|c|c|c|c|c|c|c|}
\hline \multirow{2}{*}{\multicolumn{2}{|c|}{ Case }} & \multirow{2}{*}{$\begin{array}{c}\text { Age } \\
\text { (years) } \\
\& \\
\text { Sex }\end{array}$} & \multicolumn{4}{|c|}{ Neurological manifestation } & \multirow{2}{*}{$\begin{array}{c}\text { Activity level } \\
\text { of daily living } \\
\text { (ADL) }\end{array}$} \\
\hline & & & $\begin{array}{c}\text { Education } \\
\text { level }\end{array}$ & $\begin{array}{l}\text { Concious- } \\
\text { ness }\end{array}$ & $\begin{array}{c}\text { Motor } \\
\text { disturbance* }\end{array}$ & $\begin{array}{c}\text { Sensory } \\
\text { disturbance* }\end{array}$ & \\
\hline 1 & $1 \mathrm{TS}$ & $63 \mathrm{M}$ & Standard & Alert & None & Hemihypesthesia & Class II \\
\hline 2 & $\mathrm{KT}$ & $48 \mathrm{~F}$ & Standard & Alert & None & None & Class I \\
\hline 3 & UT & $48 \mathrm{~F}$ & High & Alert & None & Paresthesia & Class I \\
\hline 4 & $\mathrm{KK}$ & $57 \mathrm{M}$ & Standard & Alert & Moderate & Hemihypesthesia & Class II \\
\hline 5 & $\mathrm{NI}$ & $61 \mathrm{M}$ & Standard & Alert & Mild & Hemihypesthesia & Class II \\
\hline 6 & $\mathrm{NI}$ & $50 \mathrm{~F}$ & Standard & $\begin{array}{l}\text { Alert } \\
\text { occasi }\end{array}$ & $\begin{array}{c}\text { Moderate } \\
\text { onally confuse }\end{array}$ & $\begin{array}{l}\text { Hemianesthesia } \\
\mathrm{d}\end{array}$ & Class III \\
\hline 7 & $\mathrm{AY}$ & $55 \mathrm{~F}$ & Standard & Alert & None & None & Class II \\
\hline 8 & SK & $63 \mathrm{~F}$ & Standard & Alert & None & None & Class I \\
\hline & $\mathrm{TT}$ & $61 \mathrm{~F}$ & Standard & Alert & Mild & Hemihypesthesia & Class II \\
\hline 10 & $\mathrm{HT}$ & $68 \mathrm{~F}$ & Standard & Alert & Mild & Paresthesia & Class II \\
\hline 11 & $\mathrm{OT}$ & $52 \mathrm{M}$ & Standard & Alert & Mild & Hemianesthesia & Class II \\
\hline 12 & $\mathrm{YK}$ & $60 \mathrm{M}$ & Standard & $\begin{array}{l}\text { Alert } \\
\text { occasi }\end{array}$ & $\begin{array}{c}\text { Moderate } \\
\text { onally confuse }\end{array}$ & Hemianesthesia & Class III \\
\hline
\end{tabular}

${ }^{*}$ Minimal motor and sensory disturbances that disappeared within $24 \mathrm{hr}$ are included in the normal level.

Class I, recovery to social life ; Class II, independent home life ; Class III, dependent home life with partial self-care; Class VI, Bed-ridden.

the rhythmic capabilities and the highly functional system in the brain. It is composed of 6 items including 40 questions as previously reported (Nakamura et al. 1981a, 1984) and is outlined in Table 6. Briefly stated the instrumentation and the test administered are as follows.

\section{Instrumentation}

Perception rhythm test. A high drum and a buzzer were required to produce the auditory rhythmic pattern and sequences. The auditory input of the Test A-(1) and the Test A-(3) were presented with the drum sounds, while the buzzer was employed in presenting the auditory input of the Test A-(2). These auditory inputs of the rhythmic pattern and its sequences for the complete experiments were prerecorded on magnetic tape and played to the subjects.

Expression rhythm test. The instrumentation to measure the performance of rhythm expression (finger-tapping) was required. We devised the instrument "Tapping-Measure" (Nakamura et al. 1981a, patent pending), and it was employed in the present study. The "Tapping-Measure" includes an electronic key, a pen-recorder, a transducer, and an auditory feedback circuit. Tapping pressure and its duration were automatically recorded as the tapping-waves on the recording paper by the pen-recorder of our instrument. The auditory feedback circuit of the instrument can produce what the subject taps in concurrent with the subject's tapping. The reproduced sounds are presented to the subject just the same condition as the human's speech mechanism can give us. 


\section{Thalamic hemorrhaged patients}

Left thalamic hemorrhage

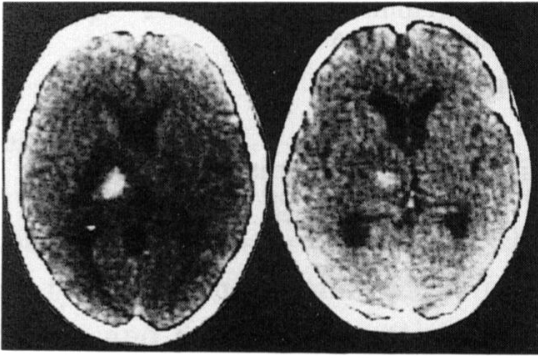

Case I

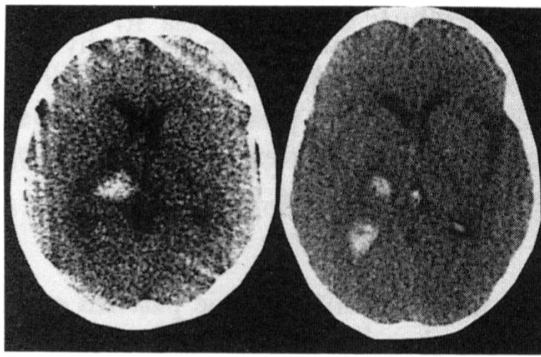

Case 3

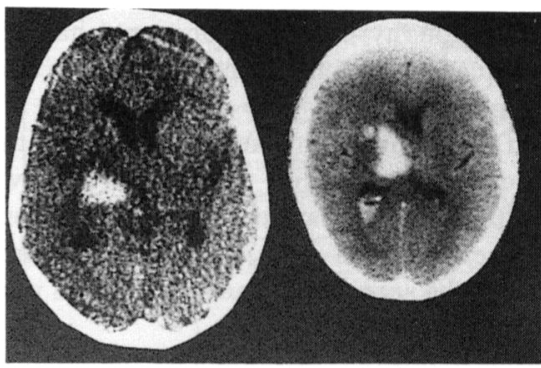

Case 5
Case 2

Case 4

Case 6
Right thalamic hemorrhage

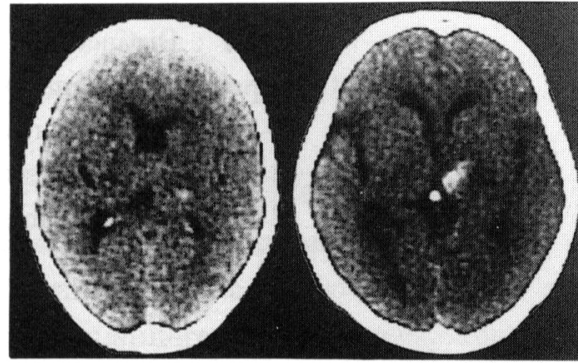

Case 7

Case 8

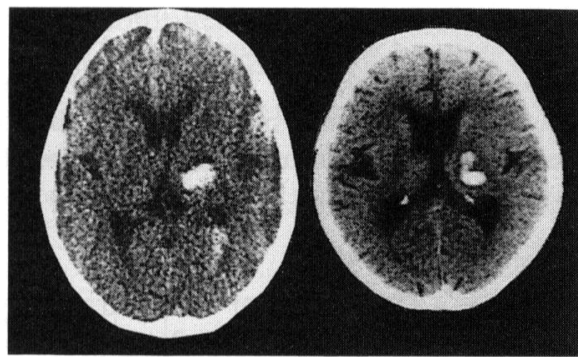

Case 9

Case 10

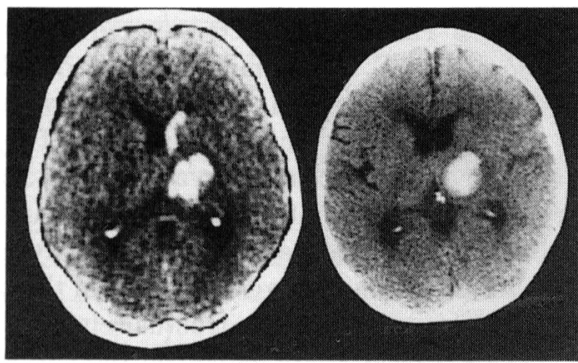

Case 12

Fig. 1. CT scan of 12 cases of thalamic hemorrhage.

TABle 5. Content of language test

1 Auditory spoken language

2 Language expression

3 Reading comprehension

4 Writing
Word, sentence, letter (Kana)

Naming, word and sentence repetition, Conversational language, Verb,

Word storage, Kanji and Kana reading (loud)

Kanji word, Kana word, sentence, Kana (letter)

Kanji word, Kana word, sentence, Kana (letter) 
TABLE 6. Content of the Asian rhythm test

A Perception rhythm tsest: Auditory discrimination

A-I : Distinction of rhythmic pattern

A-II : Distinction of rhythm- sequence

A-III : Distinction of rhythmic structure

B Expression rhythm test: Finger-tapping

B-I : Imitating rhythmic pattern

B-II : Repeating sequential rhythmic patterns

B-III : Keeping time with rhythm- sequences

\section{Test administered}

The rhythmic patterns employed in our test were based on the linguistic theories (Liberman and Prince 1977; Nakamura and Kuwahara 1979; Nakamura 1980, 1981). These patterns can be usually found out in our daily speech activities, and each rhythmic pattern is composed of two, three, of four rhythmic constituents, corresponding to the structure of a syllable or a word. These rhythmic patterns were presented almost at the same speed as our normal speech (750 msec-1.5 sec/one rhythmic pattern, $185-555 \mathrm{msec} / \mathrm{one}$ rhythmic constituent). They were tested with each trial after some training trials.

\section{Perception rhythm test}

Test $A-(I)$. This test consisted of 10 pairs of the identical rhythmic patterns or the different ones with an interpulse interval of $2 \mathrm{sec}$ and then the subjects were required to report if the two rhythmic patterns of a pair were the 'same' or 'different (not same)'. Each rhythmic pattern was repeated four times with about $200 \mathrm{msec}$ interval.

Test $A-(I I)$. The rhythmic pattern was repeated seven times successively without an interval. Then, the subjects were required to report if the rhythmic patterns were 'changed' or 'no changed' in the middle of the rhythmic sequence. Each rhythmic sequence was presented once per trial, and five trials were undergone.

Test $A$-(III). This test consisted of 5 pairs of the identical rhythmic structures or the different ones with an interval of $2 \mathrm{sec}$, the subjects were required to report if the two rhythmic structures of a pair were the 'same' or 'different'. To say more precisely, in four pairs, the rhythmic patterns of both rhythmic structures were same, but both rhythmic structures of each pair were different in the position of the accents. Then, the subjects were required to notice such a structual change in the rhythmic sequences.

This present study empolyed the natural testing condition: We provided the input to both-ears simultaneously (binaural presentation) in a free field situation. The auditory input of rhythm-sounds was presented to the subjects at a sound pressure level of $60-80 \mathrm{db}$ SPL basically, but we also tried to present the input at efficient score of the audiometry.

\section{Expression rhythm test}

Test $B-(I)$. The rhythmic pattern was presented three times successively with the 400 msec intervals, and then the subjects were required to produce one time the same rhythmic pattern that we presented: The subjects were required to tap the electronic key with the index finger in order to reproduce the rhythmic pattern. Ten trials were undergone.

Test $B-(I I)$. The rhythmic pattern was presented three times successively with no interval. Then, the subjects were required to repeat the same rhythmic pattern we presented, and also required to keep on tapping it until the 'stop' sign was presented: The subjects had to produce the rhythmic sequence. Six trials were undergone. 
Test B-(III). Each auditory stimulus consisted of 8 rhythmic sequences, and each sequence was composed of two, three, or four rhythmic patterns. Each auditory stimulus was presented twice per trial. At the first presentation, the subjects were required to follow the examiner's hand-clapping to keep times. Then, at the second presentation, the subjects were required to keep times by themselves to the presented rhythmic sounds with handclapping. Four trials were undergone.

\section{Results}

\section{Language test.}

The results of the language tests on our subjects are presented in Table 7. All patients with left cortical lesions showed significant language dysfunction, and each type of aphasia showed its own pattern of language disturbances (Fig. 2). Normals and 6 of the 20 patients in right-hemisphere damage group showed no language impairment, and the remaining 14 patients showed some difficulties in composing sentences, expressing their thoughts skillfully, producing various kinds of words or sentences, or understanding long, complex sentences. They lacked emotional expression and simplified the verbal expression of their spontaneous speech and composition. But, they could not be called aphasic. A remarkable difference in severity of language impairments was present between the left and the right hemisphere damaged patiens. While, the patients with left-sided

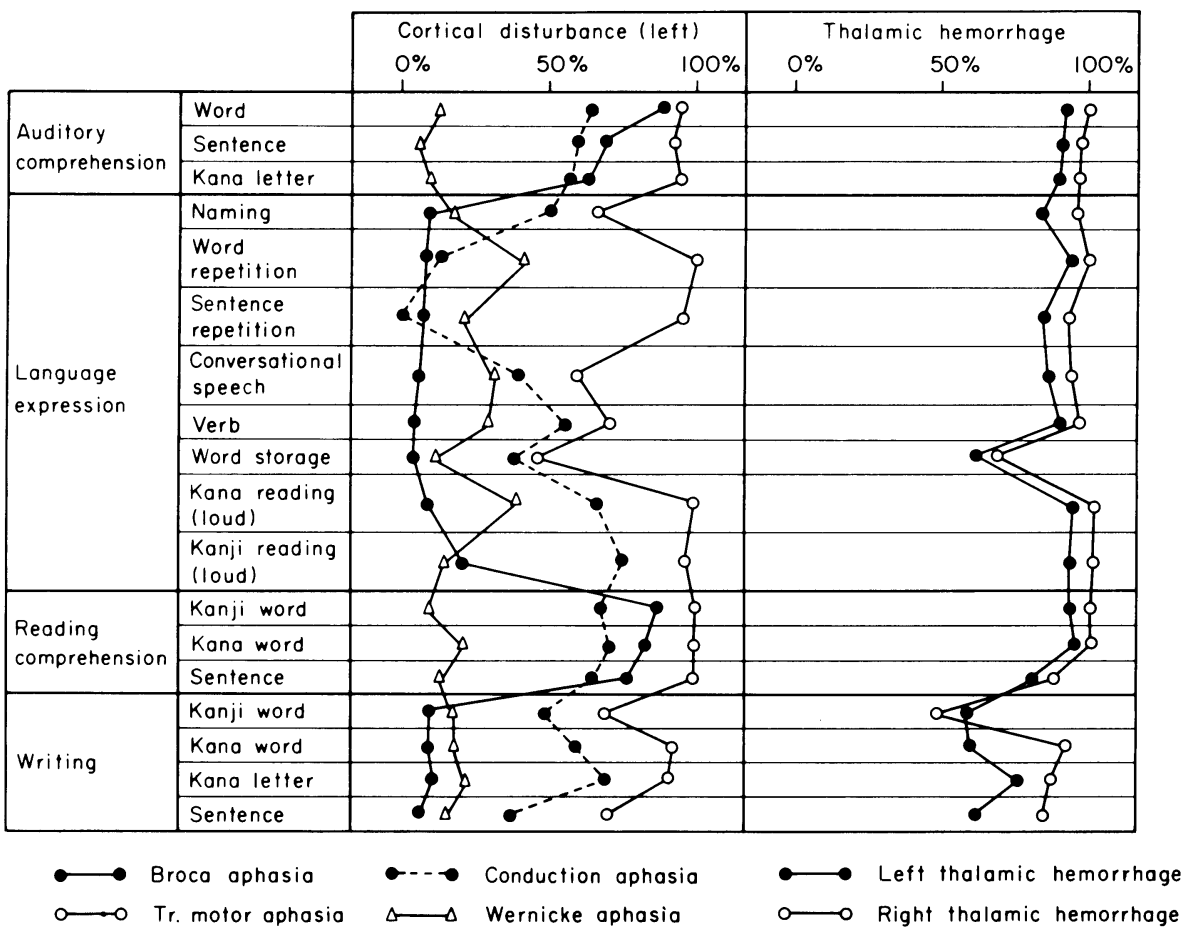

Fig. 2. A comparison of language performances of aphasics with thalamic patients. 
TABLE 7. Results of

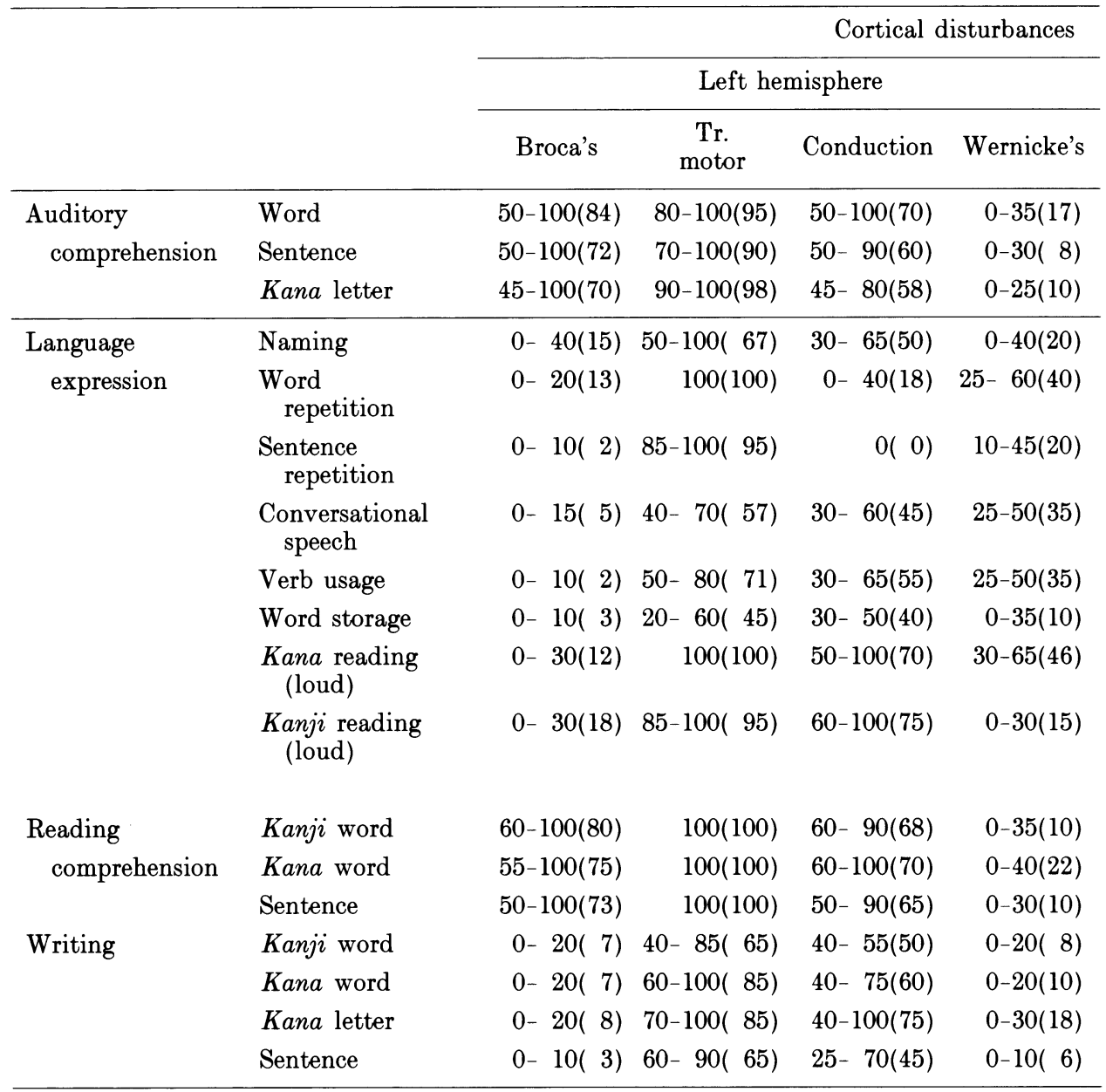

Number ( $\%)$ : Minimum - Maximum (Mean scores)

thalamic hemorrhage showed mild language impairments, but their language values were constantly higher than those of the patients with left-cortical lesions. Their language impairments were different from those caused by damage to cortical language areas (Fig. 2), and they could not be called aphasia. They did show difficulty in spelling, writing words or sentences, reading and comprehending long and complex sentences. They also showed circumstantiality, decreased attention, impaired self-control, and some difficulty in maintaining concentration. The patients with right-sided thalamic hemorrhage didn't show language impairments except slight difficulties in spelling kanji (Japanese ideograph), composing sentences, and word storage (Table 7 and Fig. 2). Of special interest is the fact that the patients with right-sided thalamic hemorrhage remarkably showed difficulty in spelling Kanji spontaneously in spite of their normal abilities in 
language tests

\begin{tabular}{|c|c|c|c|c|}
\hline & & & \multicolumn{2}{|c|}{ Thalamic hemorrhage } \\
\hline \multicolumn{3}{|c|}{ Right hemisphere } & \multirow{2}{*}{$\begin{array}{c}\text { Left } \\
\text { thalamus }\end{array}$} & \multirow{2}{*}{$\begin{array}{l}\text { Right } \\
\text { thalamus }\end{array}$} \\
\hline $\begin{array}{l}\text { Expressional } \\
\text { disturbance }\end{array}$ & $\begin{array}{l}\text { Perceptual } \\
\text { disturbance }\end{array}$ & $\begin{array}{c}\text { Good } \\
\text { prognosis }\end{array}$ & & \\
\hline $100(100)$ & $100(100)$ & $100(100)$ & $90-100(98)$ & $100(100)$ \\
\hline $90-100(90)$ & $75-90(80)$ & $100(100)$ & $70-100(85)$ & $70-100(85)$ \\
\hline $100(100)$ & $100(100)$ & $100(100)$ & $70-100(85)$ & $70-100(85)$ \\
\hline $100(100)$ & $90-100(96)$ & $100(100)$ & $60-100(78)$ & $80-100(90)$ \\
\hline $100(100)$ & $100(100)$ & $100(100)$ & $100(100)$ & $100(100)$ \\
\hline $70-90(81)$ & $70-100(88)$ & $100(100)$ & $60-100(78)$ & $80-100(88)$ \\
\hline $70-80(73)$ & $70-100(88)$ & $80-100(95)$ & $70-90(80)$ & $70-100(83)$ \\
\hline $85-100(90)$ & $100(100)$ & $100(100)$ & $80-100(90)$ & $85-100(93)$ \\
\hline $65-80(72)$ & $40-80(65)$ & $75-100(86)$ & $40-70(56)$ & $50-75(65)$ \\
\hline $100(100)$ & $100(100)$ & $100(100)$ & $100(100)$ & $100(100)$ \\
\hline $100(100)$ & $100(100)$ & $100(100)$ & $100(100)$ & $100(100)$ \\
\hline $100(100)$ & $100(100)$ & $100(100)$ & $100(100)$ & $100(100)$ \\
\hline $100(100)$ & $100(100)$ & $100(100)$ & $100(100)$ & $100(100)$ \\
\hline $80-100(91)$ & $70-100(88)$ & $100(100)$ & $60-100(75)$ & $70-100(78)$ \\
\hline $30-85(55)$ & $30-100(64)$ & $90-100(98)$ & $0-80(52)$ & $0-70(48)$ \\
\hline $45-100(75)$ & $100(100)$ & $100(100)$ & $0-80(55)$ & $80-100(90)$ \\
\hline $70-100(83)$ & $100(100)$ & $100(100)$ & $20-90(75)$ & $70-100(85)$ \\
\hline $55-85(70)$ & $55-80(68)$ & $80-100(93)$ & $0-75(53)$ & $60-100(81)$ \\
\hline
\end{tabular}

spelling Kana (Japanese phonogram) as shown in Fig. 3B. While, the patients with left-sides thalamic hemorrhage showed mild difficulty in spelling both Kana and Kanji (Fig. 3A). But, the significant right-left difference in language function noted in group with cortical lesions was not presented clearly in the thalamic hemorrhage group except the evidence of spelling above mentioned. The severity of language impairments in patients with thalamic hemorrhage correlated with the size and severity of lesions as demonstrated by CT Scans (Fig. 1) : Hyperdensity was limited to the thalamic region in the Cases (1), (2), and (3) having good language functions. While, in the Cases (5) and (6) showing some language impairment, hyperdensity involved a relatively wide region around the thalamus. The language disturbances seen in Cases (5) and (6) apparently need both the thalamic lesion and also damage in surrounding regions (Weisberg 1986). 
A

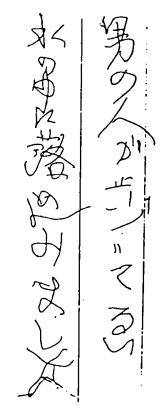

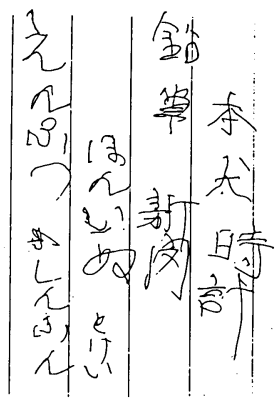

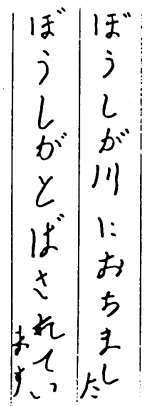

B

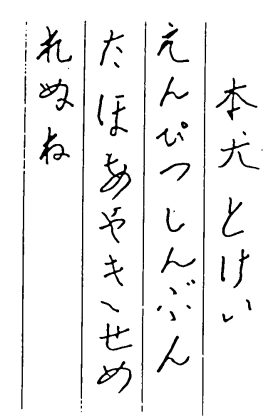

Fig. 3. Writing disturbances in cases with thalamic hemorrhage: $(A)$ Left-sided thalamic hemorrhage (Case 4), $(B)$ Right sided thalamic hemorrhage (Case $9)$.

\section{Rhythmic capabilities (temporal perception \& expression).}

The results of the rhythm test on our subjects are presented in Table 8 . These scores of Table 8 were also illustrated schematically using the six anglescore profile-chart (Fig. 4), and then Fig. 5 could be shown. All patients with cortical damage showed remarkable rhythm disturbances. In aphasics with left-hemisphere lesions, the types of rhythm disturbances appeared characteristic for the different types of aphasia. The fluent aphasia group showed reduced capabilities of perception and expression, while the non-fluent aphasics showed

TABLE 8. Results of Asian

\begin{tabular}{|c|c|c|c|c|c|c|}
\hline & & \multicolumn{4}{|c|}{ Cortical lesion in left hemisphere } & Ortical lesion \\
\hline & & Broca's & $\begin{array}{c}\text { Tr. } \\
\text { motor }\end{array}$ & Conduction & Wernicke's & $\begin{array}{l}\text { Expressional } \\
\text { disturbance }\end{array}$ \\
\hline \multicolumn{7}{|c|}{ A Parception rhythm test } \\
\hline & Test A-I (Patterning) & $\begin{array}{c}62.5 \\
(55-100)\end{array}$ & $\begin{array}{c}65.0 \\
(55-100)\end{array}$ & $\begin{array}{c}52.2 \\
(40-55)\end{array}$ & $\begin{array}{c}55.0 \\
(45-60)\end{array}$ & $\begin{array}{c}60.6 \\
(40-75)\end{array}$ \\
\hline & Test A-II (Sequencing) & $\begin{array}{c}58.5 \\
(40-80)\end{array}$ & $\begin{array}{c}70.0 \\
(50-100)\end{array}$ & $\begin{array}{c}73.3 \\
(50-80)\end{array}$ & $\begin{array}{c}41.2 \\
(20-50)\end{array}$ & $\begin{array}{c}56.8 \\
(40-65)\end{array}$ \\
\hline & Test A-III (Organizing) & $\begin{array}{c}80.0 \\
(70-100)\end{array}$ & $\begin{array}{l}100.0 \\
(100)\end{array}$ & $\begin{array}{c}75.0 \\
(50-90)\end{array}$ & $\begin{array}{c}43.1 \\
(40-60)\end{array}$ & $\begin{array}{c}85.6 \\
(75-100)\end{array}$ \\
\hline \multicolumn{7}{|c|}{ Expressional rhythm test } \\
\hline & Test B-I (Patterning) & $\begin{array}{l}18.7 \\
(0-25)\end{array}$ & $\begin{array}{c}89.4 \\
(75-100)\end{array}$ & $\begin{array}{c}21.1 \\
(10-30)\end{array}$ & $\begin{array}{c}40.6 \\
(10-60)\end{array}$ & $\begin{array}{c}71.2 \\
(65-80)\end{array}$ \\
\hline & Test B-II (Sequencing) & $\begin{array}{c}8.5 \\
(0-15)\end{array}$ & $\begin{array}{l}21.1 \\
(0-35)\end{array}$ & $\begin{array}{l}12.2 \\
(0-20)\end{array}$ & $\begin{array}{c}53.1 \\
(40-60)\end{array}$ & $\begin{array}{c}26.2 \\
(15-35)\end{array}$ \\
\hline & Test B-III (Organizing) & $\begin{array}{c}72.5 \\
(60-100)\end{array}$ & $\begin{array}{c}45.0 \\
(10-60)\end{array}$ & $\begin{array}{c}0 \\
(0)\end{array}$ & $\begin{array}{c}17.5 \\
(10-25)\end{array}$ & $\begin{array}{c}30.6 \\
(20-40)\end{array}$ \\
\hline
\end{tabular}

Number $(\%)$ : Mean scores (Minimum - Maximum) 


\section{Rating profile}

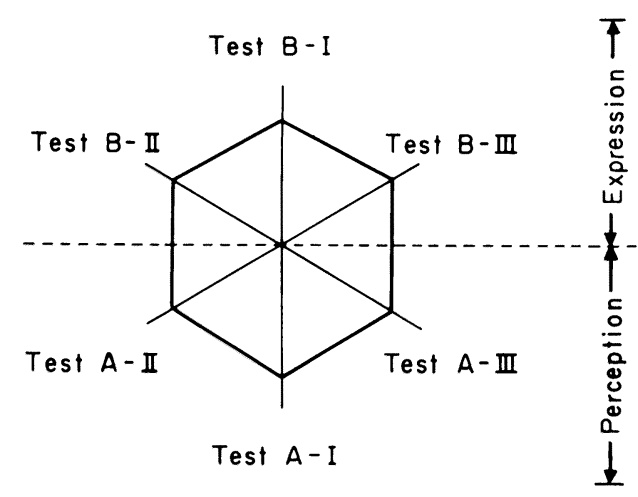

Fig. 4. The six angle-score profile chart of the Asian rhythm test.

more significant drop in expression than perception. Six out of 20 patients with lesions of the right hemisphere were close to the normal control group in performance. The remaining 14 patients, however, showed some rhythm disturbances : 7 cases with slight impairments of speech production (eg. dysarthria) showed reduced capability of rhythm expression in comparison with its perception, while 7 other cases with disturbances of mental status such as amnesia, constructional apraxia, and agnosia, showed both reduced capabilities of perception and expression. As a while, the group with lesions of the right hemisphere had better scores

rhythmic test

\begin{tabular}{|c|c|c|c|c|c|c|}
\hline \multicolumn{2}{|c|}{ in right hemisphere } & \multicolumn{2}{|c|}{ Left thalamic hemorrhage } & \multicolumn{2}{|c|}{ Right thalamic hemorrhage } & \multirow{2}{*}{$\begin{array}{l}\text { Normal } \\
\text { control }\end{array}$} \\
\hline $\begin{array}{l}\text { Perceptual } \\
\text { disturbance }\end{array}$ & $\begin{array}{c}\text { Good } \\
\text { prognosis }\end{array}$ & $\begin{array}{c}\text { Small } \\
\text { Case } 1,2,3,4\end{array}$ & $\begin{array}{c}\text { Large } \\
\text { Case 5, } 6\end{array}$ & $\begin{array}{c}\text { Small } \\
\text { Case } 7,8,9,10\end{array}$ & $\begin{array}{c}\text { Large } \\
\text { Case } 11,12\end{array}$ & \\
\hline $\begin{array}{c}44.1 \\
(30-50)\end{array}$ & $\begin{array}{c}84.1 \\
(85-100)\end{array}$ & $\begin{array}{c}62.5 \\
(50-70)\end{array}$ & $\begin{array}{c}60.0 \\
(60.0)\end{array}$ & $\begin{array}{c}76.6 \\
(70-80)\end{array}$ & $\begin{array}{c}68.3 \\
(60-75)\end{array}$ & $\begin{array}{c}88.4 \\
(75-100)\end{array}$ \\
\hline $\begin{array}{c}48.3 \\
(30-60)\end{array}$ & $\begin{array}{c}80.6 \\
(75-100)\end{array}$ & $\begin{array}{c}63.5 \\
(45-75)\end{array}$ & $\begin{array}{c}57.5 \\
(50-65)\end{array}$ & $\begin{array}{c}46.6 \\
(40-55)\end{array}$ & $\begin{array}{c}30.0 \\
(25-40)\end{array}$ & $\begin{array}{c}82.5 \\
(70-100)\end{array}$ \\
\hline $\begin{array}{c}55.0 \\
(40-65)\end{array}$ & $\begin{array}{c}87.5 \\
(85-100)\end{array}$ & $\begin{array}{l}100.0 \\
(100)\end{array}$ & $\begin{array}{c}45.0 \\
(60-30)\end{array}$ & $\begin{array}{l}100.0 \\
(100)\end{array}$ & $\begin{array}{c}48.1 \\
(40-55)\end{array}$ & $\begin{array}{c}100 \\
(100)\end{array}$ \\
\hline $\begin{array}{c}70.8 \\
(60-75)\end{array}$ & $\begin{array}{c}100 \\
(100)\end{array}$ & $\begin{array}{c}58.7 \\
(30-75)\end{array}$ & $\begin{array}{c}45.0 \\
(30-60)\end{array}$ & $\begin{array}{c}88.3 \\
(75-100)\end{array}$ & $\begin{array}{c}48.1 \\
(40-55)\end{array}$ & $\begin{array}{c}100 \\
(100)\end{array}$ \\
\hline $\begin{array}{c}65.8 \\
(50-75)\end{array}$ & $\begin{array}{c}57.5 \\
(45-65)\end{array}$ & $\begin{array}{c}36.2 \\
(30-40)\end{array}$ & $\begin{array}{l}25.0 \\
(0-50)\end{array}$ & $\begin{array}{c}48.3 \\
(40-55)\end{array}$ & $\begin{array}{c}45.0 \\
(40-50)\end{array}$ & $\begin{array}{c}100 \\
(100)\end{array}$ \\
\hline $\begin{array}{c}34.1 \\
(65-90)\end{array}$ & $\begin{array}{c}80.6 \\
(75-100)\end{array}$ & $\begin{array}{c}43.7 \\
(40-50)\end{array}$ & $\begin{array}{c}17.5 \\
(45-70)\end{array}$ & $\begin{array}{c}60.0 \\
(45-70)\end{array}$ & $\begin{array}{c}58.3 \\
(45-65)\end{array}$ & $\begin{array}{c}100 \\
(100)\end{array}$ \\
\hline
\end{tabular}


Left

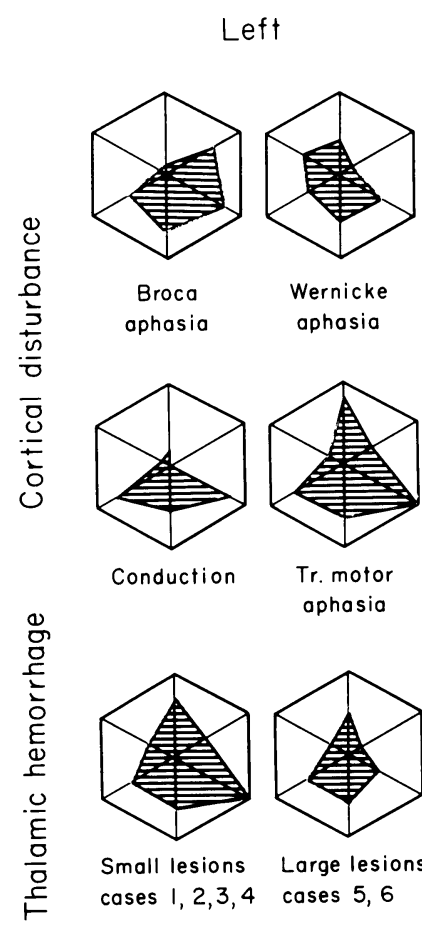

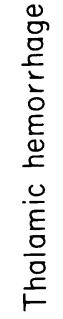
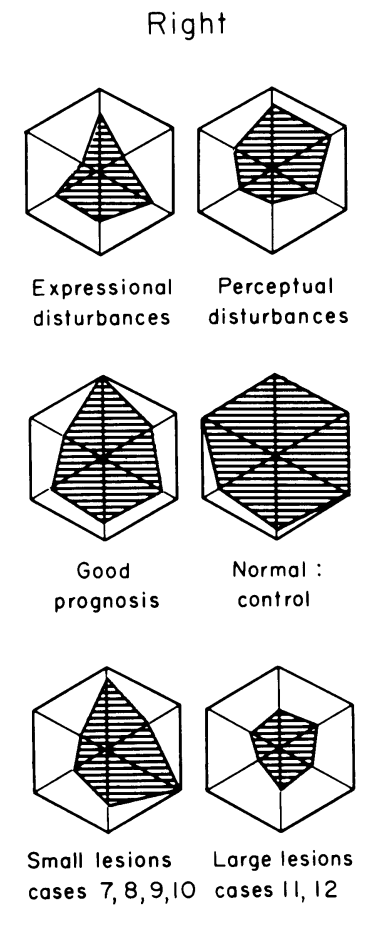

Rhythmic performances

Fig. 5. Rhythmic capabilities in our subjects.

in rhythm test than the group with lesions of left hemisphere, and a marked difference in severity and type of rhythm disturbances could be seen between the group with cortical lesions of left hemisphere and that of right hemisphere.

While all patients in the group with thalamic hemorrhage showed hypofunction, the difference caused by left and right thalamic damage was not as striking as it was in those with cortex damage. There was no specific type of rhythm disturbance peculiar only to thalamic hemorrhage ; in fact, the type seen in 10 of 12 cases of thalamic hemorrhage resembled the pattern seen in the transcortical motor aphasia in the group with cortical damage, confirming the observations of Cappa and Vignolo (1979) and Mcfarling et al. (1982) that thalamic aphasia symptoms are similar to those of transcortical motor aphasia. However, as indicated in Figs. 8 and 9, even if the rhythm disturbances are similar, a difference in the quality of tapping-wave forms can be demonstrated between those with cortical and those with thalamic damage as discussed below.

Electro tapping graph. Fig. 6 shows examples of the tapping waves in patients with cortical lesions of left hemisphere including transcortical motor aphasia (See the asterisks in Fig. 6), while Fig. 7 shows examples of the tapping waves in patients with thalamic hemorrhage. These waves are recorded by the 

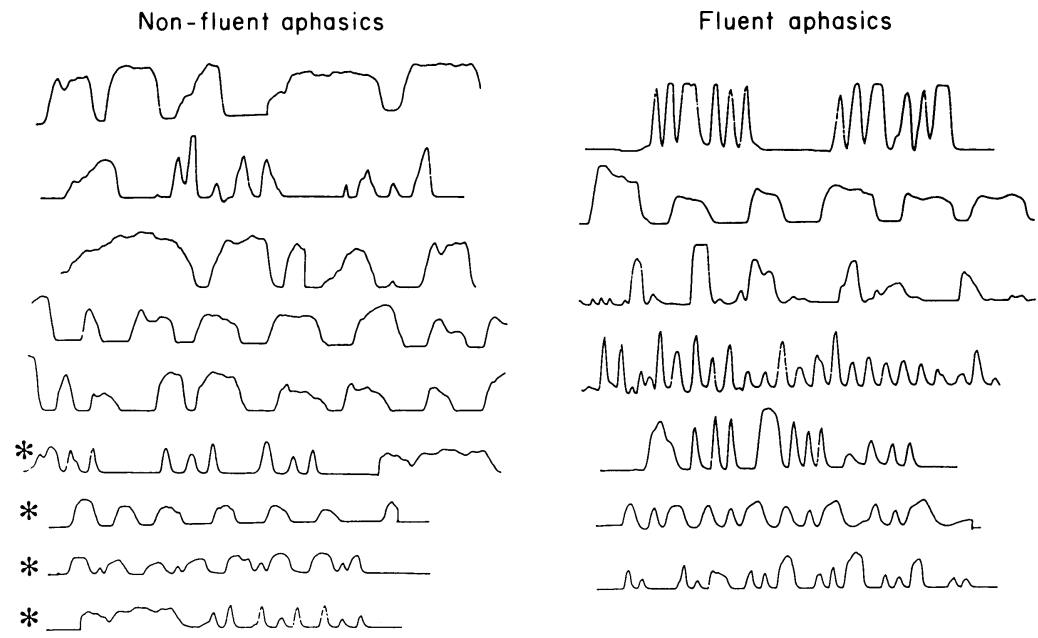

Fig. 6. Tapping waves in our aphasics with cortical lesions of left hemisphere : These waves are recorded by the Tapping-Measure (Patent Pending). The degree of tapping-pressure is recorded on the vertical line, while the degree of tapping-duration is recorded on the horizontal line. The tapping-waves marked an asterisk are present in transcortical motor aphasics.

Electro Tapping Graph, that is, the Tapping-Measure (Patent pending). The degree of tapping-pressure is recorded on the vertical line, while the degree of tapping-duration is recorded on the horizontal line. All cases with aphasia showed abnormalities in the waveforms including irregular, somewhat rough but weak, unstable tapping pressure. All aphasics showed difficulites in producing or programming how to tap rhythmic patterns. Remarkable differences in impaired waveforms distinguish each aphasia group. In contrast, the patients with thalamic hemorrhage had regular waveforms with abnormally high tapping pressure, but 4 cases with relatively wide lesions around the thalamus showed the reduced tapping pressure (See the star marks in Fig. 7). The tapping movements were maintained but they failed to reproduce rhythmic patterns presented to them. The patients with thalamic hemorrhage had difficulty in producing the appropriate rhythmic patterns, in spite of the fact that they showed no difficulty in performing movements of rhythm-tapping. They often continued tapping automatically one pattern of rhythm. They showed difficulties in connecting these auditory informations of temporal factors with the system of motor programming. Thus, a technique of the electrotapping graphy could demonstrate these dysfunctions of audio-motor coordination visually through recording tappingwaves by using the Tapping-Measure. This electro-tapping graphy also demonstrated that the remarkable difference in tapping-wave forms could be seen between aphasics with cortical lesions of the left hemisphere and the patients with left-sided thalamic hemorrhage. 


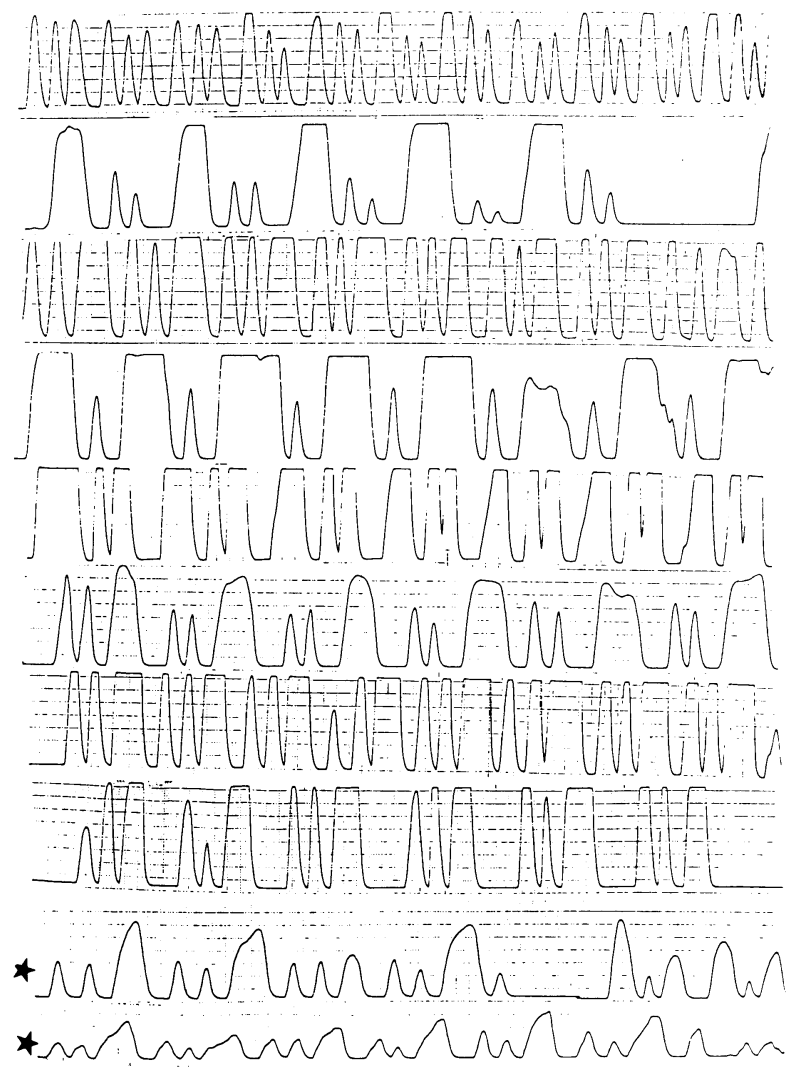

Fig. 7. Tapping waves in cases with thalamic hemorrhage. Tapping waves in patients with larger lesions around the thalamus marked a star.

\section{Discussion}

The thalamus is one of the most important structure for human's behavior in the limbic system. The thalamus relays subcortical inputs to cortical areas, and almost all thalamic nuclei have well-developed reciprocal connections with cortex. Each thalamic nucleus, especially those that are not sensory relay nuclei, has projections to multiple cortical areas. The thalamus is closely related to various parts of the brain, and therefore, the thalamus has various kinds of roles in the brain's function. And, it's clear that the thalamic dysfunction may produce many kinds of neurobehavioral deficits; motor and coordination disturbances, mental deficits, and disturbances of sensation are seen as the symptoms and signs resulting from thalamic disease. The first description of the thalamic syndrome was written by Dejerine and Roussy in 1906. It is characterised by anesthesia of one half of the body together with spontaneous pains and over-reaction to sensory stimuli and chorea. During the past few years several other cognition disorders have been described in connection with thalamic lesions; Pötzl (1946), Arnold 
and Seitelberger (1949), Von Stockert (1951) and other researchers reported the auditory disturbances associated with thalamic lesions. The disturbances in motor control were also reported by Martin (1969), Luria (1977), Guiot et al. (1961), Allen et al. (1966) and other reseachers.

Another thalamic symptom is language deficits. The first observation on thalamic aphasia was written by Dejerine and Roussy (1906), and a few years later Hillemand (1925) and Lhermitte (1936) also reported on it. Despite these early obsevations, the idea that the thalamus has an important role in the maintenance of consciousness and in the performance of higher functions has only recently been recognized. Clinical interest in the neuropsychological effects of thalamic lesions is more recent (Mateer and Ojemann 1983); Fisher (1959) reported that left but not right thalamic hemorrhages were commonly associated with a language disturbance, and Penfield and Roberts (1959) hypothesized that the thalamus was an important link between anterior and posterior cortical language areas. In the last ten years, with the advent of computerized tomographic scanning, greater numbers of cases with spontaneous thalamic lesions can be identified during life, so that detailed assessment of language function can be obtained. And the relationship of the thalamus to the mechanism of aphasic symptoms became clearer than before; Brown (1974) claimed that the disturbances of language with subcortical lesions were in only a secondary manifestation of a more global disorder of arousal. Mohr and coworkers (1975) reported that a thalamic role in regulating cerebral surface gray matter activity might be speculated. Furthermore, Ojemann and Mateer (1979) suggested that there was an attentional mechanism at a subcortical level, and also suggested that this attentional mechanism in the dominant hemisphere modulates language and verbal memory in man.

TABLE 9. Summary of results

\begin{tabular}{ccccc}
\hline & \multicolumn{2}{c}{ Cortical damaged } & \multicolumn{2}{c}{ Thalamic hemorrhage } \\
\cline { 2 - 5 } & Left & Right & Left & Right \\
\hline Language disturbance & & & & \\
Spontaneous speech & $\#$ & & + & \\
Writing Kana & $\#$ & & + & + \\
Kanji & $\#$ & + & + & \\
Rhythm disturbance & & & & \\
Auditory distinction & $\#$ & $\#$ & $\#$ & $\#$ \\
Out-put & $\#$ & $\#$ & $\#$ & \\
Tapping graph & & & & \\
Programming-loss & $\#$ & $\#$ & & \\
-Low pressure & $\#$ & + & & \\
Regulation-loss & & & $\#$ & $\#$ \\
\hline
\end{tabular}

\#, severely defective; $\#$, moderately defective $;+$, mildly defective. 


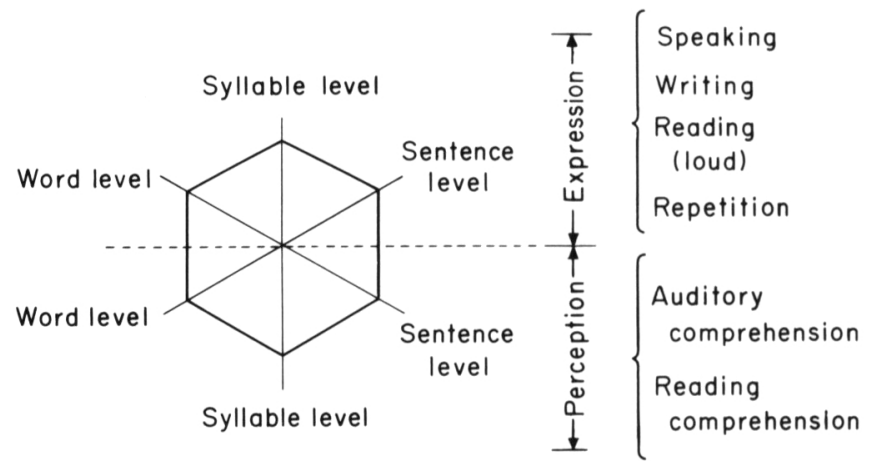

Fig. 8. The six angle-score profile chart of language test.

In this present study, the functions of language, rhythm-perception and rhythm-expression (audio-motor coordination) were investigated in the patients with cortical lesions and in the cases with thalamic hemorrhage. The results (Tables 7 and 8 ) of these investigations and the summary (Table 9) of the whole results above mentioned brought us some interesting findings to probe the relationship of the thalamus to the mechanism of aphasic symptoms. Fig. 9 illustrated schematically using the six angle-score profile charts (Figs. 4 and 8) can present a schematic comparison of rhythmic capabilities and language function in cortical

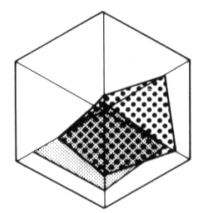

Broca aphasia

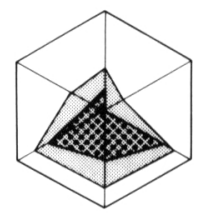

Conduction

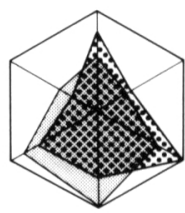

Tr. motor aphasia

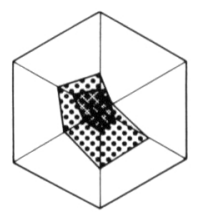

Wernicke aphasia

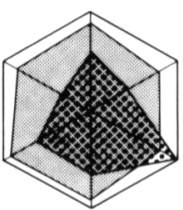

Small lesions

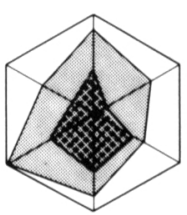

Large lesions

Khythm Language

Fig. 9. Schematic comparison of rhythmic capabilities and language function in our aphasics and patients with left thalamic hemorrhage: The six axis demonstrate respective functional values as shown in Figs. 4 and 8, while the lower three axis the perception abilities. The dots show the rhythmperformance, and the gray shows the language performance. 
damaged patients (aphasics) and in the cases with the left-sided thalamic hemorrhage.

Not surprisingly, comparison of left- and right-hemisphere damaged patients revealed marked malfunction of language and rhythmic capabilities in the group with left hemisphere lesions. Some correlation could be seen between the rhythm disturbance and the language impairments in terms of severity and types. In contrast, the patients with thalamic hemorrhage showed a dissociation between severely abnormal rhythm and milder language impairments. The language function values are constantly higher in the cases with thalamic hemorrhage than with cortical lesions of language areas, while the rhythmic capabilities are reduced, a tendency unlike that of the group with cortical damages. A remarkable difference in severity of language impairments could not seen between the left- and right-sided thalamic damaged patients, however, we found some evidence for a lateralization of Kana (Japanese phonogram) spelling to the left and Kanji (Japanese ideograph) spelling to the right at the level of the thalamus: Kana gives us phonological informations of words, while Kanji gives us visualized meanings of words. This finding is supported by Fedio and Van Buren (1975) : They reported that the right-sided brain is related to visual-spatial functions, while the left-sided one is related to language functions in the thalamocortical system.

From these observations, seveal points can be made. First, language is primarily a function of the cerebral cortex of the dominant hemisphere, while the thalamus is more closely related to rhythmic (non-verbal) functions (timing process). This finding suggests that the thalamus is not related directly to language function. This suggestion can be supported by some recent reports : the aphasic symptoms following thalamic hemorrhage is related to the effects of pressure of ischemia on the cortical areas (Benson 1979; Alexander and Loverme 1980 ; Damasio et al. 1982 ; Jonas 1982).

A second point is that both thalamus and the cerebral cortex are related to the rhythmic functions, and that the role of the thalamic area appears different from that of the cerebral cortex in the process of timing. All patients with dominant cortical lesions showed some degree of difficulty, either in producing regular tapping-waves or programming how to tap; in contrast, the thalamic patients showed little difficulty producing and programming the regular tapping-patterns. While the patients with thalamic hemorrhage produced regular tapping-waves smoothly, they had difficulty in producing the correct patterns after they were presented to both ears. This finding is in agreeement with the experiences of other investigators: Spiegel et al. (1956) reported that thalamic lesions induced "chronotaraxis (confusion of time)", and that the patients with thalamic hemorrhage made errors regarding the duration of time; Ojemann (1982) suggests that thalamic area is related to motor learning and integration of more basic motor function. Our finding can tells us the following: the cerebral cortex appears to 
play a role in analyzing and programming timing activities; the thalamic area plays an important role in balancing and integrating the functional relations between the motor and sensory systems, and also between the programming and analyzing activites.

Glosser et al. (1982) reported that thalamic patients showed difficulty in distinguishing in the hierarchic relevance of various stimulus, and also that they couldn't analyze and organize multidimensional informations. Not only language structure but also rhythmic one are generally deemed to be hierarchical (Cooper and Meyer 1960 ; Liberman and Prince 1977 ; Nakamura and Kuwahara 1979 ; Nakamura 1980, 1981), then it's quite natural that patients with thalamic lesions show some rhythm disturbance.

Our speech activities can't be performed without the process of temporal analysis and synthesis (Myklebust 1957 ; Lenneberg 1967 ; Martin 1972). It is, therefore, quite right that language disturbances can be induced by timing malfunction caused by thalamic or cortical damages (Efron 1963; Perkins 1977).

Brown (1974), Riklan and Cooper (1975), Ojemann and Mateer (1979) and others reported that thalamic aphasia (quasi-aphasia) was caused by attention-loss or arousal deficits resulted from thalamic dysfunction. While, my present study brought us the interesting suggestion: rhythm disturbances that affect language function can be induced by thalamic hemorrhage through damage to the timing mechanism. It can be, therefore, concluded that the thalamic area, necessary for the timing mechanism, plays a part in the overall mechanism of aphasic symptomatology. Further investigation and more data will be needed before the experimental implications of these findings become clear.

\section{Acknowledgments}

I am greatly indebted to Dr. D.F. Benson (Professor of UCLA, School of Medicine) for much time and effort spent advising me and rewriting part of this paper. I would also like to thank Dr. E.D. Ross (Professor, University of North Dakota School of Medicine) for his thoughtfull comment. Finally, I would like to express my gratitude to Dr. K. Kogure (Professor, Tohoku University School of Medicine) for giving me a chance to publish this paper.

\section{References}

1) Alexander, M.P. \& Loverme, S.R. (1980) Aphasia after left hemispheric intracerebral hemorrhage. Neurology, 30, 1193-1202.

2) Allen, C., Turner, J. \& Gadea-Ciria, M. (1966) Investigation into speech disturbances following stereotaxic surgery for parkinsonism. Br. J. Disord. Commun., 1, 55-59.

3) Arnold, G.E. \& Seitelberger, F. (1949) Über die thalamische Hörstörung. Klin. Med., 4, 552-564.

4) Benson, D.F. (1979) Aphasia, Alexia, and Agraphia, Churchill Livingstone, London.

5) Brown, J.W. (1974) Language, cognition and the thalamus. Confin. Neurol., 36, 33-60.

6) Cappa, S.F. \& Vignolo, L.A. (1979) Transcortical features of aphasia following left 
thalamic hemorrhage. Cortex, 15, 121-130.

7) Cooper, G. \& Meyer, L. (1960) The Rhythmic Structure of Music. University of Chicago Press, Chicago.

8) Cummings, J.L. \& Benson, D.F. (1983) Dementia : A Clinical Approach. Woburn, Mass. Butterworth, pp. 15-33.

9) Damasio, A.R., Damasio, H., Rizzo, M., Varnery, M. \& Gersh, F. (1982) Aphasia with nonhemorrhagic lesions in the basal ganglia and internal capsule. Arch. Neurol., 39, 15-20.

10) Dejerine, J. \& Roussy, G. (1906) Le syndrome thalamique. Rev. Neurol. (Paris), 14, 521-532.

11) Efron, R. (1963) Temporal perception, aphasia and déjà vu. Brain, 86, 403-424.

12) Fedio, P. \& Van Buren, J.M. (1975) Memory and perceptual deficits during electrical stimulation in the left and right thalamus and parietal subcortex. Brain Lang., 2, 78-100.

13) Fisher, C.M. (1959) The pathological and clinical aspects of thalamic hemorrhage. Trans. Am. Neurol. Ass., 84, 56-59.

14) Glosser, G., Kaplan, E. \& Loverme, S. (1982) Longitudinal neuropsychological report of aphasia following left-subcortical hemorrhage. Brain Lang., 15, 95-116.

15) Guiot, G., Hertzog, E., Rondot, P. \& Molina, P. (1961) Arrest or acceleration of speech evoked by thalamic stimulation in the course of stereotaxic procedures for parkinsonism. Brain, 84, 364-379.

16) Hillemand, P. (1925) Contribution à l'étude des syndrome de la région thalamique, Thèse, Paris.

17) Jonas, S. (1982) The thalamus and aphasia, including transcortical aphasia: A review. J. Commun. Disord., 15, 31-41.

18) Lenneberg, E.H. (1967) Biological Foundations of Language. John Wiley \& Sons, New York.

19) Lhermitte, J. (1936) Symptomatologie de l'hémorragie du thalamus. Rev. Neurol. (Paris), 65, 89-93.

20) Liberman, H. \& Prince, A. (1977) On stress and linguistic rhythm. Linguistic Inquiry, 8, 249-336.

21) Luria, A.R. (1977) On quasi-aphasic speech disturbances in lesions of the deep structures of the brain. Brain Lang., 4, 432-459.

22) Martin, J.G. (1972) Rhythmic (Hierarchical) versus serial structure in speech and other behavior. Psychol. Rev., 79, 487-509.

23) Martin, J.J. (1969) Thalamic syndromes. In: Handbook of Clinical Neurology, edited by P.J. Vinken \& G.W. Vinken, Vol. 2, pp. 469-491.

24) Mateer, C.A. \& Ojemann, G.A. (1983) Thalamic mechanisms in language and memory. In: Language Functions and Brain Organization, edited by S.T. Segalowitz, Academic Press, New York, pp. 171-191.

25) Mcfarling, D., Rothi, L.J. Heilman, K.M. (1982) Transcortical aphasia from ischemic infarcts of the thalamus: A report of two cases. J. Neurol. Neursurg. Psychiatry, 45, 107-112.

26) Mohr, J.P., Watters, W.C. \& Duncan, G.W. (1975) Thalamic hemorrhage and aphasia. Brain Lang., 2, 3-17.

27) Myklebust, H.R. (1957) Childhood aphasia : An evolving concept. In : Handbook of Speech Pathology and Audiology, edited by L.E. Travis, Printice-Hall, Inc., Engelwood Cliffs, New Jersey, pp. 1181-1202.

28) Naeser, M., Alexander, P., Helm-Estabrooks, N., Levine, H.L., Laughlin, S.A. \& Geschwind, N. (1982) Aphasia with predominantly subcortical lesion sites. Arch. Neurol., 39, 2-12.

29) Nakamura, H. (1980) Stress assignment with rhythm (Rhythmic Theory). Ann. Eng. Linguistics of Miyagi Gakuin Coll., 8, 55-94. 
30) Nakamura, H. (1981) Phonological process undergo rhythm (Rhythmic Theory II). Ann. Eng. Linguistics of Miyagi Gakuin Coll., 9, 102-145.

31) Nakamura, H. \& Kuwahara, T. (1979) Stress assignment with meter or rhythm? In: The Annals of Applied Information Science, 5, Tohoku University Press, Sendai, pp. $99-125$.

32) Nakamura, H., Nagafuchi, M., Nakamura, S. \& Kogure, K. (1981a) Analysis of rhythmic capabilities in brain-damaged patients: Correlation between speech and rhythmic functions. 12th World Congress of Neurology (Abstract), Excepta Midica, Amsterdam, pp. 116-167.

33) Nakamura, H., Nagafuchi, M., Nakamura, S. \& Kogure, K. (1981b) Rhythmic capabilities in aphasics. Higher Brain Function Res., 1, 74-75. (Japanese)

34) Nakamura, H., Nagafuchi, M., Nakamura, S. \& Kogure, K. (1984) Functional significance of the corpus callosum based on the analysis of rhythmic capabilities in the split-brain patients. Tohoku J. Exp. Med., 142, 363-379.

35) Ojemann, G.A. (1982) Interrelationship in the localization of language, memory, and motor mechanisms in human cortex and thalamus. In : New Perspectives in Cerebral Localization, edited by R.A. Thompson \& J.R. Green, Raven Press, New York, pp. 157-175.

36) Ojemann, G.A. \& Mateer, C. (1979) Human language cortex : Localization of memory, syntax, and sequential motor-phoneme identification system. Science, 205, 14011403.

37) Ojemann, G.A. \& Ward, A.A. (1971) Speech representation in ventrolateral thalamus. Brain, 91, 99-116.

38) Ojemann, G.A., Fedio, P. \& Van Buren, J.M. (1968) Anomia from pulvinar and subcortical parietal stimulation. Brain, 91, 99-116.

39) Osgood, C.E. \& Miron, M.S. (1963) Approaches to the Study of Aphasia. University of Illinois Press, Urbana.

40) Penfield, W. \& Roberts, L. (1959) Speech and Brain Mechanism. Princeton University Press, New Jersey.

41) Perkins, W.H. (1977) Speech Pathology : An Applied Behavioral Science. The C.V. Mosby Company, St. Louis.

42) Pötzl, O. (1946) Die Pathophysiologie der thalamish bedingten Hörstörung. Monatsschr. Ohrenheilk., 79, 28-36.

43) Riklan, M. \& Cooper, I.S. (1975) Psychometric studies of verbal functions following thalamic lesions in humans. Brain Lang., 2, 45-64.

44) Schuell, H., Jenkins J.J. \& Jimens-Pabon, E. (1964) Aphasia in Adults. Harper, New York.

45) Spiegel, E.A., Wycis, H.T., Orchinik, C. \& Freed, H. (1956) Thalamic chronotaraxis. Amer. J. Psychiat., 113, 97-103.

46) Von Stockert, F.G. (1951) Ein Fall von thalamischer Hörstörung. Arch. Psychiat. Nervenkr., 187, 45-68.

47) Weisberg, L.A. (1986) Thalamic hemorrhage: Clinical-CT correlations. Neurology, 36, $1382-1386$. 